\title{
Risk of death among Italian AIDS cases with AIDS-defining cancers in the post-HAART era
}

\author{
D Serraino*1, S Bruzzone ${ }^{2}$, B Suligoi ${ }^{3}$, A De Paoli ${ }^{1}$, J Polesel ${ }^{1}$, B Longo ${ }^{3}$, \\ S Boros ${ }^{3}$, P Piselli ${ }^{4}$, L Dal Maso ${ }^{1}$, L Camoni ${ }^{3}$ and G Rezza ${ }^{3}$
}

Address: ${ }^{1}$ Epidemiology and Biostatistics, IRCCS "Centro di Riferimento Oncologico, " Aviano, Italy, ${ }^{2}$ Direzione Centrale, Servizio Sanità e Assistenza, National Institute of Statistics -ISTAT-, Rome, Italy, ${ }^{3}$ National AIDS Registry, Dip. Mal. Infettive, Istituto Superiore di Sanità, Rome, Italy and "Epidemiology and Biostatics, IRCCS "L. Spallanzani", INMI, Rome, Italy

* Corresponding author

\author{
from I I th International Conference on Malignancies in AIDS and Other Acquired Immunodeficiencies (ICMAOI): Basic, Epidemiologic, and Clinical \\ Research \\ Bethesda, MD, USA. 6-7 October 2008 \\ Published: 17 June 2009 \\ Infectious Agents and Cancer 2009, 4(Suppl 2):O25 doi:I0.1 I86/I750-9378-4-S2-O25
}

This abstract is available from: http://www.infectagentscancer.com/content/4/S2/O25

(c) 2009 Serraino et al; licensee BioMed Central Ltd.

This study intended to quantify the impact of AIDS-defining cancers on the risk of death in the post-HAART era. With this aim in mind, data regarding all Italian AIDS cases reported to the National AIDS Registry were analyzed.

Between 1999 and 2005, a total of 12,433 individuals were diagnosed with AIDS in Italy. Specifically excluded from this analysis were people with AIDS who were: 1 ) not-Italian citizen $(\mathrm{n}=1918) ; 2)$ resident in Italian areas where individual information on death was not available $(\mathrm{n}=108) ; 3)$ resident in unknown areas $(\mathrm{n}=119) ; 4)$ pediatric or vertical transmission cases $(n=50) ; 5)$ diagnosed solely at autopsy $(n=576)$. The presence of AIDSdefining cancers (i.e., Kaposi's sarcoma-KS, non-Hodgkin lymphoma-NHL, and invasive cervical cancer-ICC) at AIDS diagnosis is routinely ascertained at the National AIDS Registry, together with some other information, including age, sex, date of AIDS diagnosis, HIV transmission category, CD4+ cells count. Information on vital status of AIDS cases, as of December 2006, was assessed through a semi-automated linkage procedure, ensuring confidentiality of individual data, with the national death certificates database. Survival function was estimated by the Kaplan-Meier method; Cox regression model was used to estimate death hazard ratios (HR), and corresponding $95 \%$ confidence intervals (CI), associated to the presence of AIDS-defining cancers at diagnosis, adjusted for age at
AIDS diagnosis, sex, HIV transmission category, and CD4+ cells count at diagnosis.

Of the 9,662 AIDS cases included in the present study, 478 had KS, 429 immunoblastic NHL, 158 Burkitt's lymphoma, 69 ICC, and 58 NHL of the central nervous system (CNS). As of December 2006, 3,096 deaths were registered: of these deaths, 505 occurred among cases with AIDS-defining cancers. The proportion of AIDS cases still alive 5 years after AIDS diagnosis was 66.6 percent. The shortest survival period was seen among individuals diagnosed with CNS NHL (median survival $=4$ months), followed by those with immunoblastic NHL or Burkitt's lymphoma (median survival $=16$ and 38 months, respectively), whereas the longest ones were recorded among cases with ICC or KS (median not reached). In comparison with AIDS cases without AIDS-defining cancers, those with a CNS NHL had a 4.7 -fold higher risk of death (95\% CI: 3.5-6.4), those with immunoblastic NHL or Burkitt's lymphoma had more than twice the risk (HR $=2.6,95 \%$ CI: 2.2-2.9; and HR $=2.3,95 \%$ CI: $1.8-2.8$, respectively), and, among women, those with ICC had a 1.8 -fold elevated risk (95\% CI: 1.2-2.7). Conversely, among individuals with $\mathrm{KS}$ (HR $=0.7,95 \% \mathrm{CI}$ : 0.6-0.9) the risk of death was lower than that of cases without AIDS-defining cancers. 
In conclusion, this exhaustive survival analysis of Italian AIDS cases in the post-HAART era highlighted the persisting lethality of NHL and the long survival of cases with KS and ICC.

Publish with Bio Med Central and every scientist can read your work free of charge

"BioMed Central will be the most significant development for disseminating the results of biomedical research in our lifetime. " Sir Paul Nurse, Cancer Research UK

Your research papers will be:

- available free of charge to the entire biomedical community

- peer reviewed and published immediately upon acceptance

- cited in PubMed and archived on PubMed Central

- yours - you keep the copyright 